\title{
斜投象における軸測軸系の変動範囲 *
}

竹 山 和 彦**

\section{まえがき}

斜投象において, 空間の互いに直交する 3 直線の像すなわち軸測軸の縮率 $\mathrm{e}_{1}, \mathrm{e}_{2}, \mathrm{e}_{3}$ 及び画面と投射線の交角 $\left(90^{\circ}-\phi\right)$ の間に次式が成立する。

$$
\mathrm{e}_{1}^{2}+\mathrm{e}_{2}^{2}+\mathrm{e}_{3}^{2}=2+\tan ^{2} \phi
$$

しかし(1)式は投射線と画面の交角及び軸測軸の縮率の関係を総合して表したものであって， それぞれの軸の縮率及び軸測軸の間の角は如何なるものであるかは明確でない。

著者は前論文 ${ }^{1)}$ において，平行投象の軸測軸を，画面に垂直な直線と投射線それぞれの方向 余弦により表し，画面上の任意の直線を共有する平面束に投象される軸測軸の計算式を導き， 等測投象の例によって軸測軸の一軸を共有する平面束に投象される軸測軸の変化について考察 した。以上のように, 画面上の直 線を軸として画面を回転する方法 はある特定の方向に関する投射線 の傾角の変化による軸測軸の変化 を知るには便利であるが，画面と 投射線の交角が一定であるときに 軸測軸が変化する状況を明確に示 すことは困難である。

本論文は，前論文が空間の直交 座標系と投射線の関係を固定して 画面と投射線の交角を変化させた のに対し，原点を通る投射線を軸 として空間の直交座標系を回転さ せ，投射線の傾角が一定である場 合の斜投象における軸測軸の変動 範囲を明確に示すものであり，前 論文と相まって平行投象の軸測軸 の全貌を明らかにするものである。

\section{投射線となす角が一定な直線の 縮率}

Fig. 1 は一対の正投象と, 立面 図が端形図 $\mathrm{s}^{\prime}$ で表される平面 $\mathrm{S}$ の実形（副投象，左上の図）を表 したものである。図の如くY軸を 基線の方向に一致させ, $\mathrm{Z}$ 軸を平

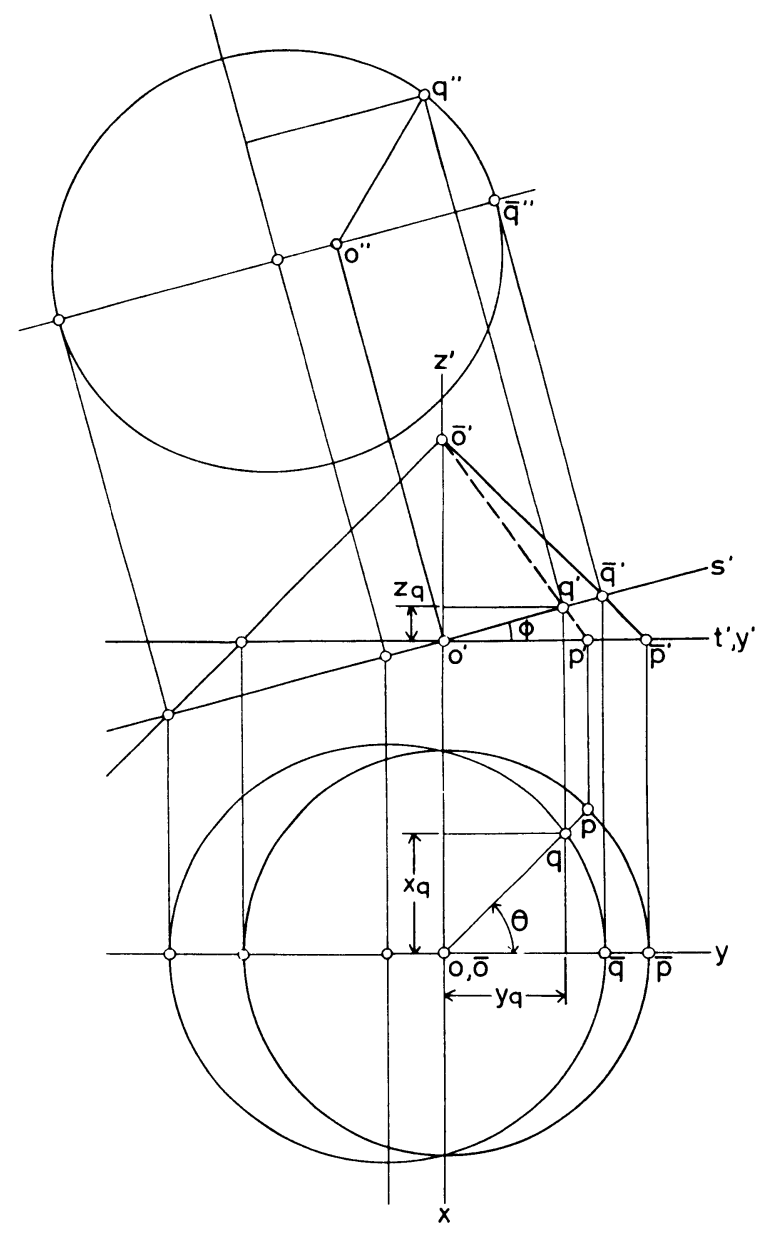

Fig. 1 


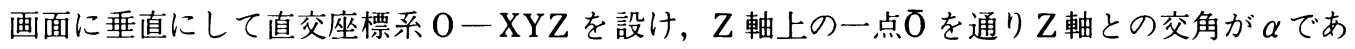
る直線 $\mathrm{OP}$ を $\mathrm{Z}$ 軸 $(\bar{O} O)$ を軸として回転させ， Z 軸すなわち 00 の方向へ平行投象して平面 $\mathrm{S}$ に生ずる直線 $\bar{O} \mathrm{P}$ の像の確率について考える。

点 $\mathrm{P}$ が $\mathrm{Y}$ 軸上にあるときを $\overline{\mathrm{P}}$ とし $\overline{\mathrm{O}} \overline{\mathrm{P}}$ と平面 $\mathrm{S}$ の交点を $\overline{\mathrm{Q}}$ とする。 $\mathrm{O} \overline{\mathrm{Q}}$ は平面 $\mathrm{S}$ の最大勾配 を表す直線（最大勾配線）で $\angle \overline{\mathrm{Q}} \mathrm{OP}$ は平面 $\mathrm{S}$ の水平傾角 $\phi$ (平画面と平面 $\mathrm{S}$ の交角, したがっ て投射線と平面 $\mathrm{S}$ の交角は $90^{\circ}$ - $\phi$ である）を表す。いま $\triangle$ OOP の OO を軸とする回転角 $\theta$ を $\triangle \overline{O O P}$ から反時計回りに測るものとし， OO の長さを $\mathrm{h}$ とすれば， OP と平面 $\mathrm{S}$ の交点 $\mathrm{Q}$ の座 標 $\mathrm{Xq}, \mathrm{Yq}, \mathrm{Zq}$ は次式で表される。

$$
\begin{aligned}
& \mathrm{Xq}=\frac{-\mathrm{h} \sin \theta}{\tan \phi \cos \theta+\cot \alpha}, \mathrm{Y}_{\mathrm{q}}=\frac{\mathrm{h} \cos \theta}{\tan \phi \cos \theta+\cot \alpha} \\
& \mathrm{Z}_{\mathrm{q}}=\frac{\mathrm{h} \tan \phi \cos \theta}{\tan \phi \cos \theta+\cot \alpha}
\end{aligned}
$$

したがって直線 $\overline{O Q} の$ 像 $\mathrm{OQ}$ の縮率 $\mathrm{e}(=\mathrm{OQ} / \overline{\mathrm{O}})$ は次式で表される。

$$
\mathrm{e}=\sin \alpha \sqrt{1+\tan ^{2} \phi \cos ^{2} \theta}
$$

点 $\mathrm{P}$ が平画面上を $\mathrm{O}$ を中とする円運動を行うとき点 $\mathrm{Q}$ は図の如く楕円運動を行うが，上式に よって明らかな如く縮率 $\mathrm{e}$ は回転角 $\theta$ にともなって連続的に変化し, 中心 $\mathrm{O}$ に関して対称であ る。縮率 $\mathrm{e}$ の最大值は像 $\mathrm{OQ}$ が平面 $\mathrm{S}$ の最大勾配線 $\left(\mathrm{Q}=0^{\circ}, 180^{\circ}\right)$ に一致したときで,

$$
\mathrm{e}_{\max }=\sin \alpha \sqrt{1+\tan ^{2} \phi}
$$

となり，縮率 $\mathrm{e}$ の最小值は像 $\mathrm{OQ}$ が平面 $\mathrm{S}$ に含まれる水平線 $\left(\mathrm{Q}=90^{\circ}, 270^{\circ}\right)$ に一致したとき で，次式で表され正軸測投象の縮率に等しい。

$$
\mathrm{e}_{\min }=\sin \alpha
$$

\section{投射線の傾角が一定である斜投象の 軸測軸}

Fig. 2 はFig. 1 と同様に,一対の正投 象と, 立面図が端形図 $\mathrm{s}^{\prime}$ で表される平面 $\mathrm{S} の$ 実形（副投象, 左上の図）を表した ものである。いま空間の直交座標系 $\bar{O}-$ $\overline{\mathrm{X}} \overline{\mathrm{Y}} \overline{\mathrm{Z}}$ の $\overline{\mathrm{X}}$ 軸を立画面に平行な位置に設 け， Oから平画面へ下した垂線の足を $\mathrm{O}$ とし， 00 を軸として空間の直交座標系 を $\theta$ だけ回転させた 投射線とする平面 $\mathrm{S} へ$ 平行投象を考之 る。このとき平画面の跡三角形 $\overline{\mathbf{a}} \mathbf{b} \mathbf{c}$ は 点 $\mathrm{O}$ を中として回転して $\triangle \mathrm{abc}$ へ移動 $(\triangle \mathrm{abc} \equiv \Delta \overline{\mathrm{a}} \overline{\mathrm{b}} \mathrm{c})$ ） し, 平面 $\mathrm{S}$ に生ずる跡 三角形 $\bar{d}^{\prime \prime} \mathrm{e}^{-\prime} \mathrm{f}^{-\prime \prime}$ は $\triangle \mathrm{d}^{\prime \prime} \mathrm{e}^{\prime \prime} \mathrm{f}^{\prime \prime}$ 一移動する。

平画面に生ずる正軸測軸系を $\mathrm{O}-\mathrm{xyz}$, 縮率を $\mathrm{e}_{\mathrm{x}}, \mathrm{e}_{\mathrm{y}}, \mathrm{e}_{\mathrm{z}}$, 軸測軸の間の角を $\theta_{\mathrm{xy}}, \theta_{\mathrm{y} z}, \theta_{z \mathrm{x}}$, とし, 空間の直交座標系

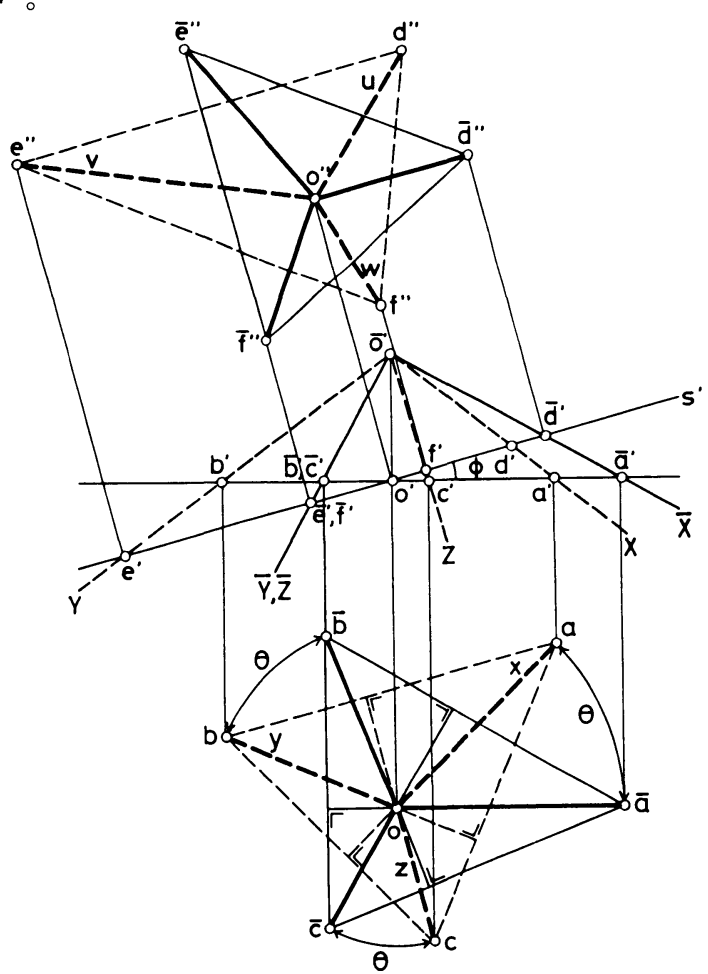

Fig. 2 
$\overline{\mathrm{O}}-\mathrm{XYZ} の \mathrm{X} ， \mathrm{Y} ， \mathrm{Z}$ 各軸と投射線のなす角を $\alpha, \beta, \gamma$ ，投射線の方向余弦を $\ell_{\mathrm{x}}, \ell_{\mathrm{y}}, \ell_{\mathrm{z}}$ とすれば，正軸測軸系における諸量は $\theta$ に関係なく次式で表される。

$$
\begin{aligned}
& \ell_{\mathrm{x}}=\cos \alpha, \quad \ell_{\mathrm{y}}=\cos \beta, \quad \ell_{\mathrm{z}}=\cos \gamma \\
& \mathrm{e}_{\mathrm{x}}=\sin \alpha, \quad \mathrm{e}_{\mathrm{y}}=\sin \beta, \quad \mathrm{e}_{\mathrm{z}}=\sin \gamma \\
& \cos \theta_{\mathrm{xy}}=-\cot \alpha \cot \beta, \quad \cos \theta_{\mathrm{yz}}=-\cot \beta \cot \gamma, \quad \cos \theta_{\mathrm{zx}}=-\cot \gamma \cot \alpha
\end{aligned}
$$

平面 $\mathrm{S}$ に生ずる斜軸測軸系（ $\overline{\mathrm{O}}-\mathrm{XYZ}$ の 00 を投射線とする平面 $\mathrm{S} へ$ の投象）を $\mathrm{O}$ 一 uvw, 縮率を $\mathrm{e}_{\mathrm{u}}, \mathrm{e}_{\mathrm{v}}, \mathrm{e}_{\mathrm{w}}$, 軸測軸の間の角を $\theta_{\mathrm{uv}}, \theta_{\mathrm{vw}}, \theta_{\mathrm{wu}}$ とし, 平面 $\mathrm{S}$ に垂直な直線と空間の直交 座標系 $\mathrm{O}$ - XYZ の各軸となす角を $\alpha^{\prime}, \beta^{\prime}, \gamma^{\prime}$, 平面 $\mathrm{S}$ に垂直な直線の方向余弦を $\mathrm{m}_{\mathrm{x}}, \mathrm{m}_{\mathrm{y}}$, $\mathrm{m}_{\mathrm{z}}$ とすれば，前節と同様にして，斜軸測軸系における諸量は $\theta$ の関数として次式で表される。

$$
\begin{aligned}
& \mathrm{m}_{\mathrm{x}}=\cos \alpha^{\prime}=\sin \alpha \cos \phi(\tan \phi \cos \theta+\cot \alpha) \\
& \mathrm{m}_{\mathrm{y}}=\cos \beta^{\prime}=\sin \beta \cos \phi\left[\tan \phi \cos \left(\theta+\theta_{\mathrm{xy}}\right)+\cot \beta\right] \\
& \mathrm{m}_{\mathrm{z}}=\cos \gamma^{\prime}=\sin \gamma \cos \phi\left[\tan \phi \cos \left(\theta-\theta_{\mathrm{zx}}\right)+\cot \gamma\right] \\
& e_{u}=\sin \alpha \sqrt{1+\tan ^{2} \phi \cos ^{2} \theta} \\
& \mathrm{e}_{\mathrm{v}}=\sin \beta \sqrt{1+\tan ^{2} \phi \cos ^{2}\left(\theta+\theta_{\mathrm{xy}}\right)} \\
& \mathrm{e}_{\mathrm{w}}=\sin \gamma \sqrt{1+\tan ^{2} \phi \cos \left(\theta-\theta_{\mathrm{zx}}\right)} \\
& \cos \theta_{\mathrm{uv}}=\frac{\cos \theta_{\mathrm{xy}}+\tan ^{2} \phi \cos \theta \cos \left(\theta+\theta_{\mathrm{xy}}\right)}{\sqrt{\left(1+\tan ^{2} \phi \cos ^{2} \theta\right)\left[1+\tan ^{2} \phi \cos ^{2}\left(\theta+\theta_{\mathrm{xy}}\right)\right\rfloor}} \\
& \cos \theta_{\mathrm{vw}}=\frac{\cos \theta_{\mathrm{yz}}+\tan ^{2} \phi \cos \left(\theta+\theta_{\mathrm{xy}}\right) \cos \left(\theta-\theta_{\mathrm{zx}}\right)}{\sqrt{\left(1+\tan ^{2} \phi \cos ^{2}\left(\theta+\theta_{\mathrm{xy}}\right)\right]\left[1+\tan ^{2} \phi \cos ^{2}\left(\theta-\theta_{\mathrm{zx}}\right)\right]}} \\
& \cos \theta_{\mathrm{wu}}=\frac{\left.\cos \theta_{\mathrm{zx}}+\tan ^{2} \phi \cos \left(\theta-\theta_{\mathrm{zx}}\right)\right]}{\sqrt{\left[1+\tan ^{2} \phi \cos ^{2}\left(\theta-\theta_{\mathrm{zx}}\right)\right]\left(1+\tan ^{2} \phi \cos ^{2} \theta\right)}}
\end{aligned}
$$

となり, $\cos \left(\theta+\theta_{\mathrm{xy}} / 2\right)=1$ すなわち $\theta=-\theta_{\mathrm{xy}} / 2$ のとき最小で

$$
\theta_{\mathrm{uv} \min }=\cos ^{-1} \frac{\cos \theta_{\mathrm{xy}}\left(2+\tan ^{2} \phi\right)+\tan ^{2} \phi}{\left(2+\tan ^{2} \phi\right)+\cos \theta_{\mathrm{xy}} \tan ^{2} \phi}
$$

となる。

以上を要約すると, 投射線の傾角が一定である斜投象の軸測軸は, 空間の直交座標系の原点 を通る投射線を軸とする回転に伴って連続的に変化し，縮率は軸の方向が投射線の正射影の方 向に一致したとき最大となり，投射線の正射影に直交する方向に一致したとき最小となる。軸 測軸の間の角はその角の二等分線の方向が投射線の正射影の方向に一致したとき最小となり， 投射線の正射影に直交する方向に一致したとき最大となる。 


\section{計算例}

空間の直交座標系 $\bar{O}-\overline{\mathrm{X}} \overline{\mathrm{Y}} \overline{\mathrm{Z}}$ の $\overline{\mathrm{O}}$ を頂点とする直角三面角の軸を投射線とする平行投象の場 合について軸測軸の変動する様相を示す。

このとき，直投象は等測投象を与える。前節と同様に投射線と $\overline{\mathrm{X}}$ 軸で決定される平面を画面 の最大勾配線の方向にとり，その位置からの投射線を軸とする回転角 $\theta$ と，X軸の像 $\mathrm{u}$ 軸の縮 率 $\mathrm{e}_{\mathrm{u}}$ 及び $\mathrm{X}$ 軸と $\mathrm{Y}$ 軸の像すなわち $\mathrm{u}$ 軸と $\mathrm{v}$ 軸の間の角 $\theta_{\mathrm{uv}}$ の関係を，画面に垂直な直線と， 投射線のなす角 $\phi$ （直投象の場合の画面と斜投象の場合の画面との交角）をパラメータとして Fig. 3 及びFig. 4 に図示した。

前論文では，等測投象の一軸（Z軸）を軸として画面を回転した場合（回転角 $\phi ，$ 前論文で は $\theta)$ について図示したが，本計算例では画面と投射線の交角が一定 $\left(90^{\circ}-\phi\right)$ の場合の軸測 軸の全貌を示したものであって，縮率及び軸測軸の間の角の最大值から最小值まで図示されて いる。前論文の $\theta$ は本論文の $\phi$ に対応し, 前論文の $\mathrm{e}_{\mathrm{x} 3}, \mathrm{e}_{\mathrm{y} 3}$ は本論文の $\mathrm{e}_{\mathrm{u}}$ の $\theta=30^{\circ}$ の場合 に，前論文の $\theta_{\mathrm{y} z 3}, \theta_{\mathrm{zx} 3}$ は本論文の $\theta_{\mathrm{uv}}$ の $\theta=90^{\circ}$ の場合にそれぞれ相当する。

この計算例から，画面の垂線が投射線となす角が小さい間は，軸測軸の直投象からの偏倚は 小さいことがわかる。
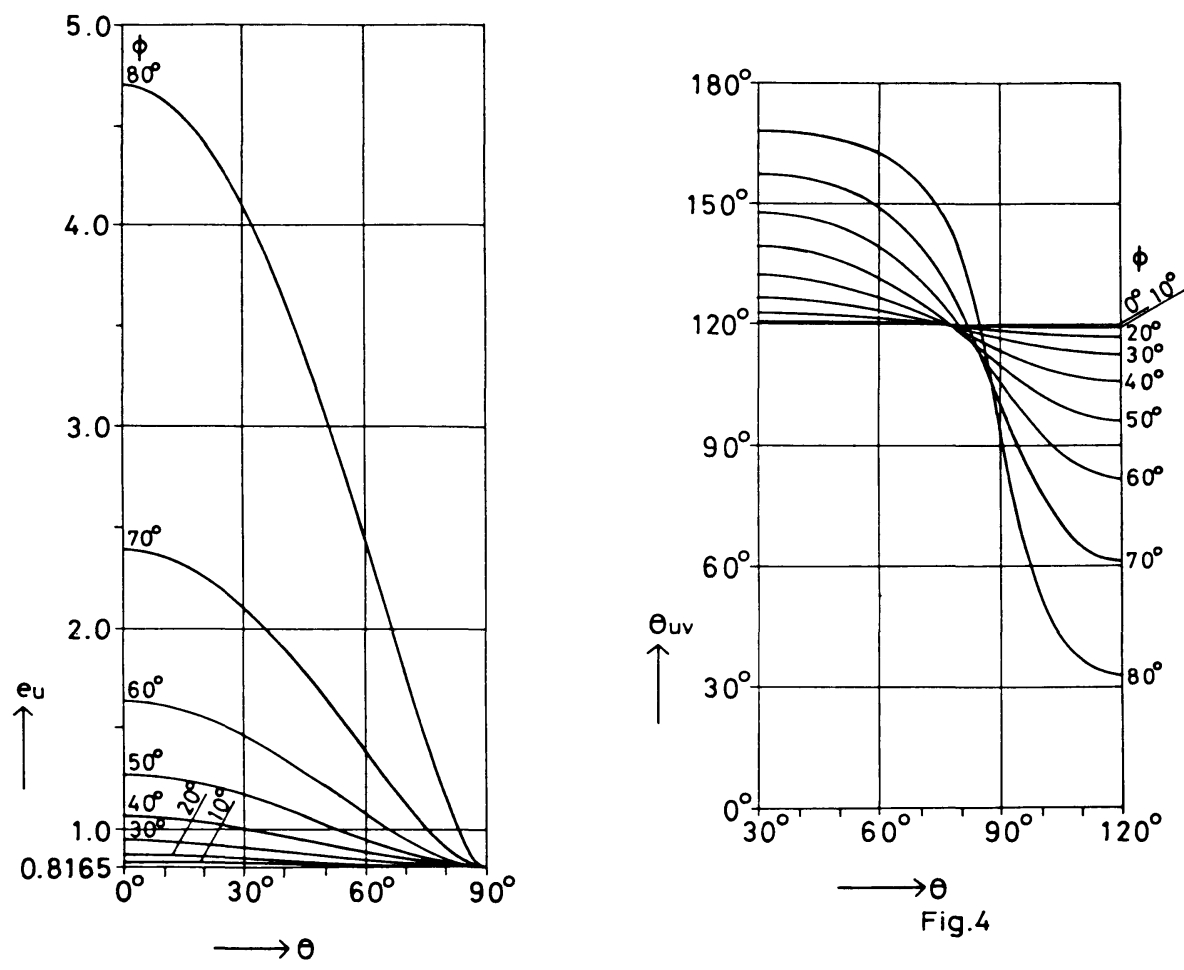

Fig. 3

\section{参考交献}

1 ）竹山和彦：平行投象の軸測軸に関する研究, 図学研究, 第32号, 1983. 3 


\section{補遭}

Fig. 2 の平面 $\mathrm{S}$ に生ずる軸測軸 $\mathrm{u} ， \mathrm{v} ， \mathrm{w}$ の水平傾角（平画面との交角）をそれぞれ $\phi_{\mathrm{u}}$, $\phi_{\mathrm{v}}, \phi_{\mathrm{w}}$ とおくと

$$
\begin{aligned}
& \tan \phi_{\mathrm{u}}=\tan \phi \cos \theta \\
& \tan \phi_{\mathrm{v}}=\tan \phi \cos \left(\theta+\theta_{\mathrm{xy}}\right) \\
& \tan \phi_{\mathrm{w}}=\tan \phi \cos \left(\theta-\theta_{\mathrm{zx}}\right)
\end{aligned}
$$

なる関係があるので，(10)，(11)式は次式の如く簡単に表現できる。

$$
\left.\begin{array}{l}
\mathrm{e}_{\mathrm{u}}=\mathrm{e}_{\mathrm{x}} / \cos \phi_{\mathrm{u}}, \mathrm{e}_{\mathrm{v}}=\mathrm{e}_{\mathrm{y}} / \cos \phi_{\mathrm{v}}, \mathrm{e}_{\mathrm{w}}=\mathrm{e}_{\mathrm{w}}=\mathrm{e}_{\mathrm{z}} / \cos \phi_{\mathrm{w}} \\
\cos \theta_{\mathrm{uv}}=-\frac{\cos \alpha \cos \beta}{\mathrm{e}_{\mathrm{u}} \mathrm{e}_{\mathrm{v}}}+\sin \phi_{\mathrm{u}} \sin \phi_{\mathrm{v}} \\
\cos \theta_{\mathrm{vw}}=-\frac{\cos \beta \cos \gamma}{\mathrm{e}_{\mathrm{v}} \mathrm{e}_{\mathrm{w}}}+\sin \phi_{\mathrm{v}} \sin \phi_{\mathrm{w}} \\
\cos \theta_{\mathrm{wu}}=-\frac{\cos \gamma \cos \alpha}{\mathrm{e}_{\mathrm{w}} \mathrm{e}_{\mathrm{u}}}+\sin \phi_{\mathrm{w}} \sin \phi_{\mathrm{u}}
\end{array}\right\}
$$

以上の式は，斜軸測軸が正軸測軸の平行投象であることを表すものである。

また(6)，(7)，(9)式から
$\mathrm{e}_{\mathrm{x}} \tan \phi \cos \theta=\mathrm{m}_{\mathrm{x}} / \cos \phi-\ell_{\mathrm{x}}$
$\mathrm{e}_{\mathrm{y}} \tan \phi \cos \left(\theta+\theta_{\mathrm{xy}}\right)=\mathrm{m}_{\mathrm{y}} / \cos \phi-\ell_{\mathrm{y}}$
$\mathrm{e}_{\mathrm{z}} \tan \phi \cos \left(\theta-\theta_{\mathrm{zx}}\right)=\mathrm{m}_{\mathrm{z}} / \cos \phi-\ell_{\mathrm{z}}$

なる関係があって(10)，(11)式は前論文の式と一致する。 その他

$$
\begin{aligned}
& \mathrm{e}_{\mathrm{u}}^{2}+\mathrm{e}_{\mathrm{v}}^{2}+\mathrm{e}_{\mathrm{w}}^{2}=2+\tan ^{2} \phi \\
& \ell_{\mathrm{x}} m_{\mathrm{x}}+\ell_{\mathrm{y}} m_{\mathrm{y}}+\ell_{\mathrm{z}} m_{\mathrm{z}}=\cos \phi
\end{aligned}
$$

から，以下の式が成立する。

$\mathrm{e}_{\mathrm{x}}^{2} \tan ^{2} \phi_{\mathrm{u}}+\mathrm{e}_{\mathrm{y}}^{2} \tan \phi_{\mathrm{v}}+\mathrm{e}_{\mathrm{z}}^{2} \tan ^{2} \phi_{\mathrm{w}}=\tan ^{2} \phi$

$\mathrm{e}_{\mathrm{x}}^{2} \cos ^{2} \theta+\mathrm{e}_{\mathrm{y}}^{2} \cos ^{2}\left(\theta+\theta_{\mathrm{x} y}\right)+\mathrm{e}_{\mathrm{z}}^{2} \cos ^{2}\left(\theta-\theta_{\mathrm{zx}}\right)=1$

$\sin 2 \alpha \tan \phi_{\mathrm{u}}+\sin 2 \beta \tan \phi_{\mathrm{v}}+\sin 2 \gamma \tan \phi_{\mathrm{w}}=0$

$\sin 2 \alpha \cos \theta+\sin 2 \beta \cos \left(\theta+\theta_{\mathrm{xy}}\right)+\sin 2 \gamma \cos \left(\theta-\theta_{\mathrm{zx}}\right)=0$ 

Variation-Range of Axonometric Co-ordinate System in oblique Projection

\section{KazUhiko TAKEYAMA}

In the parallel projection, the distortions of the oblique ones to the orthogonal projection can be described by the angle made when projecting lines and image plane cross. This paper shows the variation-range of the axonometric coordinate system, consisting of the image unit and the angle of adjacent image axes, in the case of the oblique projection in which the angle made by the projecting line and the image plane is constant. 